\title{
Simulasi Pembelajaran Berternak Burung Puyuh Menggunakan Metode Finite State Machine Berbasis Android
}

\author{
Indra Dharma Wisjaya \\ Program Studi Teknik Informatika, \\ Jurusan Teknologi Informasi, \\ Politeknik Negeri Malang \\ Malang, Indonesia \\ IndraDharma@gmail.com
}

\author{
Nindy Alvi Fajarina \\ Program Studi Teknik Informatika, \\ Jurusan Teknologi Informasi, \\ Politeknik Negeri Malang \\ Malang, Indonesia \\ nindyalvif@gmail.com
}

\author{
Dian Hanifudin Subhi \\ Program Studi Teknik Informatika, \\ Jurusan Teknologi Informasi, \\ Politeknik Negeri Malang \\ Malang, Indonesia \\ Dhanifudin@gmail.com
}

\begin{abstract}
Simulation games summarize an activity or activities carried out by humans in the form of a game where there is a learning process and reciprocity provided by the user by utilizing artificial intelligence. The application is built in the form of simulation as a learning medium on how to raise quails. Learning covers the process of hatching eggs until the quail has been rejected or cannot produce eggs anymore. In this application, artificial intelligence is implemented with the Finite State Machine (FSM) method to make it easier to regulate the behavior of objects when there are changes in conditions or conditions during the maintenance process of quail. From the results of testing the application blackbox has been going well and from the results of the questionnaire that has been distributed, it was found that the application was good to be applied with a percentage of $77.7 \%$. The results of whitebox testing are done by comparing the process of maintenance games with the structure of the design using the FSM method running well. Thus, the results of this application can be used as a learning medium for users who will and or have raised quails so that it is expected to increase knowledge to be applied when raising quails.
\end{abstract}

Keywords — simulation; breeding; quail; finite state machine

Abstrak - Simulation game merangkum suatu kegiatan atau aktivitas yang dilakukan manusia kedalam bentuk game dimana terjadi suatu proses pembelajaran dan timbal balik yang diberikan oleh pengguna dengan memanfaatkan kecerdasan buatan. Aplikasi yang dibangun berbentuk simulasi sebagai media pembelajaran mengenai cara berternak burung puyuh. Pembelajaran meliputi proses penetasan telur hingga pada masa burung puyuh telah afkir atau tidak dapat memproduksi telur lagi. Pada aplikasi ini diimplementasikan kecerdasan buatan dengan metode Finite State Machine (FSM) agar mempermudah dalam mengatur perilaku dari objek saat terjadi perubahan keadaan atau kondisi selama proses pemeliharaan pembudidayaan burung puyuh. Dari hasil pengujian blackbox aplikasi telah berjalan dengan baik dan dari hasil kuesioner yang telah disebarkan, diperoleh bahwa aplikasi sudah baik untuk di terapkan dengan prosentase sebesar $\mathbf{7 7 , 7 \%}$. Hasil pengujian whitebox yang dilakukan dengan membandingkan proses permainan pemeliharaan dengan struktur rancangan menggunakan metode FSM berjalan dengan baik. Dengan demikian, Hasil dari aplikasi ini dapat dijadikan media pembelajaran bagi pengguna yang akan dan atau telah berternak burung puyuh sehingga diharapkan dapat menambah pengetahuan untuk diterapkan pada saat berternak burung puyuh.

Keywords - simulasi; berternak; burung puyuh; finite state machine

\section{PENDAHULUAN}

Budidaya burung puyuh semakin diminati oleh sejumlah masyarakat pedesaan salah satunya di Desa Rejowinangun, Kecamatan Kademangan, Kabupaten Blitar. Banyaknya masyarakat yang menaruh minat untuk menjalankan bisnis budidaya burung puyuh, tidak terlepas dari beberapa keuntungan burung puyuh itu sendiri. peminat dari kalangan pegawai yang menjadikan budidaya burung puyuh ini sebagai usaha sampingan dan peternak pemula, dari kedua pihak tersebut lebih memilih mencari pekerja untuk melakukan semua pekerjaan dalam proses pembudidayaan burung puyuh. Padahal disisi lain pemilik usaha sebaiknya mengerti dan mengetahui proses apa saja yang perlu dilakukan dan hal apa saja yang perlu dihindari selama pembudidayaan burung puyuh untuk mengantisipasi kemungkinan buruk yang terjadi.

Pada penelitian sebelumnya telah diteliti game simulasi menggunakan finite state machine untuk pertanian dan peternakan, dimana dalam game tersebut terdapat alur cerita permainan berbasis simulasi pertanian dan juga peternakan [1]. Selain itu penggunaan FSM dalam game juga di lakukan pada game cstle of illusion oleh Achmad Badrudin [2].

Pada aplikasi ini diimplementasikan kecerdasan buatan dengan metode Finite State Machine (FSM) yang dimana akan mempermudah mengatur perilaku dari objek saat terjadi perubahan keadaan atau kondisi selama proses pemeliharaan pembudidayaan burung puyuh.

Tujuan pembuatan aplikasi ini yakni dapat membangun sebuah media simulasi pembelajaran berternak burung puyuh dengan menerapkan metode FSM (Finite State Machine) untuk menentukan perilaku dan perawatan pada saat proses pemeliharaan burung puyuh.

\section{BUDIDAYA BURUNG PUYUH}

Budidaya burung puyuh adalah bisnis atau usaha yang bergerak dalam memelihara dan atau memproduksi hewanhewan ternak. Budidaya menurut bahasa peternakan dapat diartikan sebagai sektor produksi hewan ternak. Ada juga sebahagian orang mengartikan budidaya ini sebagai pengembangbiakan, padahal sekedar penggemukan atau pengasuhan saja juga bisa disebut sebagai budidaya ternak. [11]

Budidaya berbeda dengan pemuliaan ternak, dalam budidaya bukan saja kegiatan pemeliharaan yang terdapat di dalamnya, kegiatan perkembang biakan (reproduksi) juga 
termasuk di dalam usaha budidaya. Hampir semua jenis hewan dapat dibudidayakan, bila hewan tersebut hewan liar maka terlebih dahulu dilakukan proses pemuliaan. Dibutuhkan manajemen pemeliharaan yang baik di dalam melakukan budidaya ini.

Burung Puyuh merupakan jenis burung yang tidak dapat terbang, ukuran tubuh relatif kecil dan berkaki pendek. Banyaknya peminat untuk menjalankan usaha bururng puyuh tidak lepas dari beberapa keuntungan burung puyuh itu sendiri. Beberapa pemanfaatan burung puyuh diantaranya usaha telur burung puyuh, daging afkir, bulu burung puyuh, kotoran burung puyuh.[10]

Dalam pembudidayaan burung puyuh memiliki beberapa fase yang akan ditemui. Mulai dari pemilihan bibit untuk menghasilkan telur untuk calon yang ditetaskan, penetasan telur, pemeliharaan, hingga panen telur, dan terakhir pasca panen dengan menjual puyuh yang tergolong puyuh afkir.

Dalam pemeliharaan burung puyuh ada beberapa hal yang perlu diperhatikan. Pemberian pakan (makan) dan minum, pemberian pakan pada burung puyuh dapat berupa bentuk pallet, remah-remah dan tepung. Pada puyuh anakan maupun dewasa sebaiknya diberi pakan 2 kali dalam sehari, yaitu pagi sekitar sehabis subuh hingga pukul 07.00 dan sore sekitar pukul 16.00.

Pakan yang diberikan berupa pallet, remah -remah, tepung, dan juga mineral. Pemberian pakan disesuaikan dengan umur puyuh. Untuk puyuh yang berumur 0 sampai 30 hari diberi pakan pallet 511. Untuk puyuh yang berusia diatas 0 hari diberi pakan yang telah dicampur. Campuran pakan tersebut terdiri dari pallet BP sebanyak $1 / 2$ kwintal, Katul sebanyak $30 \mathrm{~kg}$, pallet Layer SLC sebanyak $10 \mathrm{~kg}$, Kunir sebanyak $1 / 2 \mathrm{~kg}$ dan Mineral sebayak $1 \mathrm{~kg}$.

Sanitasi dan pencegahan, untuk mencegah timbulnya penyakit ternak pada burung puyuh, sebaiknya sanitasi lingkungan kandang harus dijaga dengan baik dan agar tidak menyebabkan penyakit yang tidak di inginkan. Selain itu kegiatan vaksinasi yang juga mencegah timbulnya penyakit. Berikut tabel 1 merupakan daftar kegiatan vaksinasi yang pada umumnya dilakukan oleh peternak burung puyuh:

Tabel 1 Pemberian vaksinasi pada burung puyuh

\begin{tabular}{|l|l|l|}
\hline No. & \multicolumn{1}{|c|}{ Umur Puyuh } & Jenis Vaksin dan vitamin \\
\hline 1. & 7 hari & ND C500 \\
\hline 2. & 14 hari & ND La Sota C1000 \\
\hline 3. & 30 hari & - -Vita Stress \\
\hline 4. & 37 hari & Vitamin Medi egg \\
\hline 5. & 2 bulan & Semprot antibiotic \\
\hline
\end{tabular}

Pemberian vitamin Medi egg dapat dilakukan setiap 2 minggu sekali untuk meningkatkan produksi telur dn dapat menjegah stress. Selain itu untuk pencegahan penyakit dilakukan penyemprotan antibiotic yang dapat dilakukan setiap 2 bulan sekali.

Penerangan kandang dan sirkulasi kandang dalam pemeliharaan burung puyuh maka yang harus diperhatikan adalah memperhatikan ketersediaan cahaya matahari yang cukup supaya puyuh mendapat vitamin D yang cukup dan alami dari sinar matahari tersebut.
Pembersihan kandang dilakukan setiap 4 hari sekali. Hal ini sekaligus mencegah terserangnya penyakit yang berasal dari kotoran puyuh.

Penyakit yang sering menyerang burung puyuh ialah pilek. Penanganan yang dilakukan antara lain pemberian obat yang dicampurkan kedalam minumannya. Jika penyakit sudah parah, burung puyuh dipisahkan ke kandang yang berbeda untuk mendapatkan perawatan khusus hingga kondisinya membaik baru dikembalikan ke kandang semula.[4][5].

\section{FINITE STATE MACHINE (FSM)}

Finite State Machine (FSM) terdiri dari serangkaian state yang menentukan pengambilan keputusan. Setiap state dapat berpindah ke state lainnya jika memenuhi kondisi yang telah ditentukan sebelumnya [3]

Finite State Machine (FSM) merupakan sebuah mesin abstrak yang berfungsi untuk mendefinisikan sekumpulan kondisi yang menentukan kapan suatu state harus berubah. Setiap state yang sedang dijalankan tersebut menentukan perilaku yang terjadi pada objek yang bersangkutan. Diagram state FSM digambarkan pada gambar 1 sebagai berikut, [7]

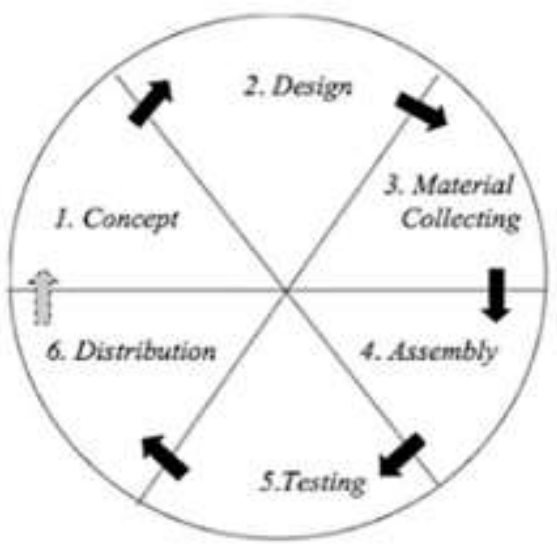

Gambar 1 Merupakan Diagram state Finite State Machine

Finite State Automata (FSA) sama dengan FSM. FSA bukanlah mesin fisik tetapi suatu model matematika dari suatu sistem yang menerima input dan output. FSA merupakan mesin automata dari bahasa regular (tipe 3). Perubahan state dinyatakan oleh fungsi transisi. Suatu FSA secara formal dinyatakan oleh 5 (lima) tupel $\mathrm{M}=(\mathrm{Q}, \Sigma, \delta$, S, F) dimana:

- $\mathrm{Q}=$ Himpunan State/ kedudukan

- $\Sigma=$ himpunan symbol input/ masukan

- $\Delta=$ Fungsi transisi

- $\mathrm{S}=$ State awal/ kedudukan awal

- $\mathrm{F}=$ Himpunan state akhir

FSA berdasarkan pada pendefinisian kemampuan perubahan statenya bisa dikelompokkan kedalam Deterministic Finite Automata (DFA) dan Non Deterministic Finite Automata (NFA). Pada DFA dari suatu state ada tepat satu state berikutnya untuk setiap simbol input (masukan) yang diterima. Pada NFA dari suatu state bisa terdapat nol (0) atau satu (1), atau lebih busur keluar (transisi) berlabel symbol yang sama. Jadi setiap pasangan 
state input, bisa memiliki 0 atau lebih pilihan untuk state berikutnya [4].

\section{METODE}

\section{A. Pengumpulan Data}

Tahapan pengumpulan data ini dilakukan untuk memperoleh data dan informasi yang diperlukan dalam pembuatan aplikasi simulasi pembelajaran berternak burung puyuh, seperti pengumpulan materi yang akan dimasukkan dalam aplikasi serta pengumpulan referensi penunjang terkait dengan pembuatan aplikasi.

\section{B. Perancangan Sistem}

Tahap Perancangan dan desain sistem dalam pembuatan apikasi simulasi pembelajaran berternak burung puyuh menggunakan metode Multimedia Development Life Cycle (MDLC) yang digambarkan pada gambar 6.1. Metode ini terdiri dari beberapa fase yaitu konsep (concept) berupa WBS (Work Breakdown Structure), design (design) yang meliputi stroryboard, dan aktifitas diagram, pengumpulan bahan (material collecting), pembuatan (assembly), pengujian (testing), dan distribusi (distribution).

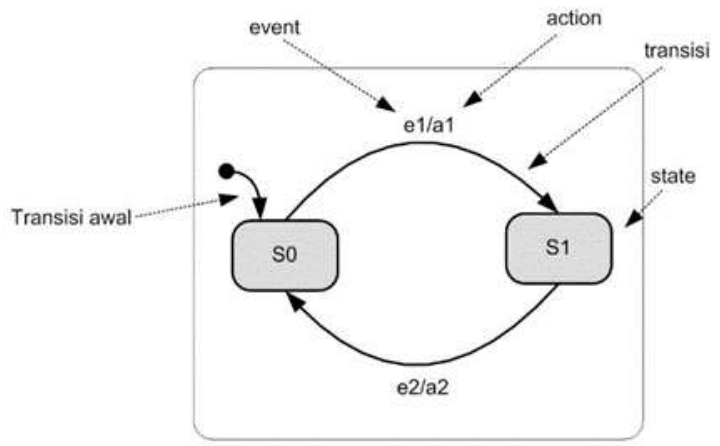

Gambar 2 Diagram Multimedia Development Life Cycle

\section{Usecase diagram}

Usecase pada aplikasi berhubungan dengan interaksi user terhadap sistem. Pada diagram use case yang ditunjukan pada gambar 3 menjelaskan masing-masing deskripsi dari UseCase diagram yang dilakukan oleh user dalam penggunaan aplikasi.

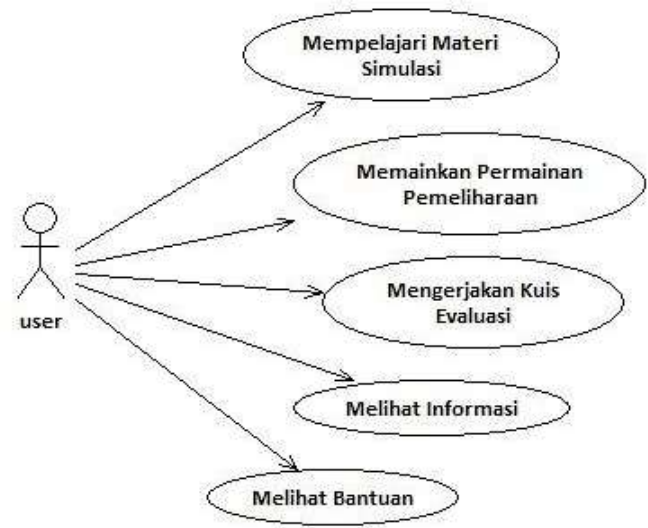

Gambar 3 Usecase Diagram

2. Storyboard aplikasi.

Pada tabel 1 berikut merupakan storyboard fitur

Tabel 2 Storyboard fitur aplikasi

\begin{tabular}{|c|c|c|c|c|}
\hline No. & Penjelasan \\
kondisi sehat & Puyuh lesu & \\
\hline 2. & &
\end{tabular}




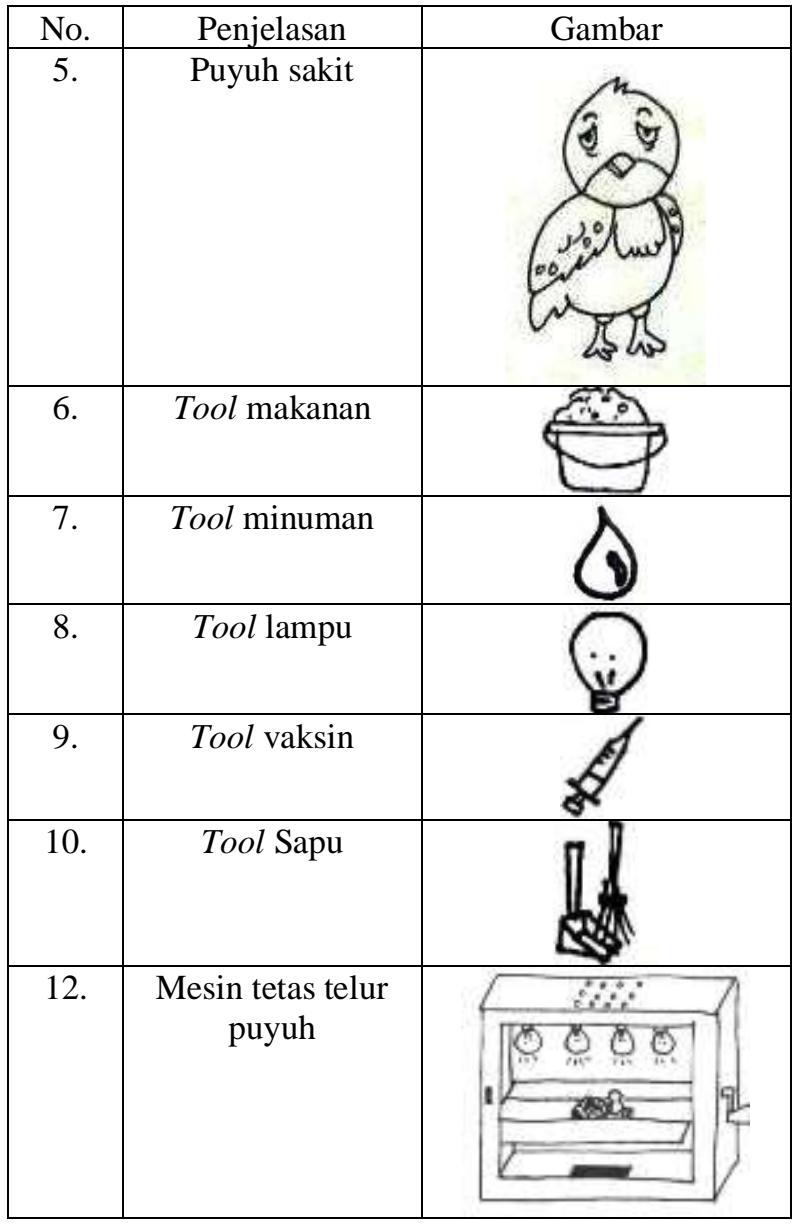

HASIL DAN PENGUJIAN

A. Implementasi Desain Antar Muka

Pembuatan aplikasi simulasi pembelajaran beternakbrung puyuh dimulai dengan pembuatan assets yaitu sprite dan gambar lingkungan permainan. Sprite merupakan gambar - gambar yang mewakili objek dalam suatu game. Software yang digunakan pada tahap ini adalah Adoce Illustrator CC 2014.

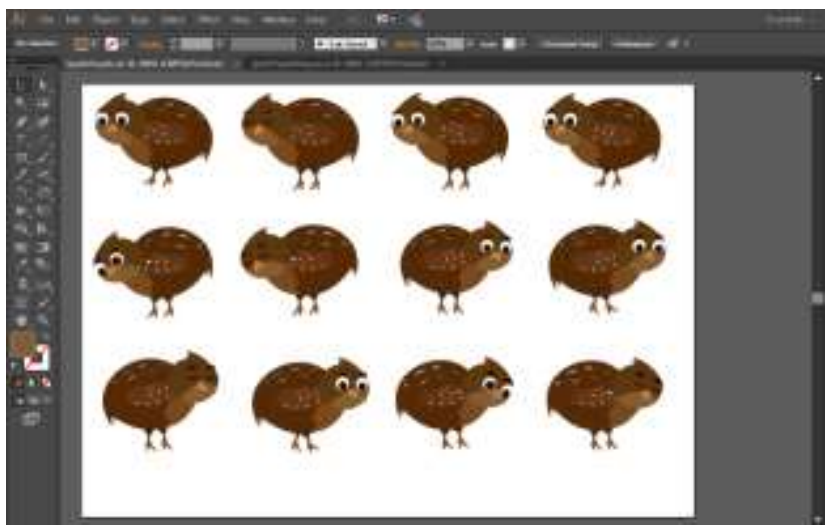

Gambar 4.Pembuatan sprite karakter puyuh menggunakan Adobe Illustrator

Aplikasi yang digunakan untuk membangun game ini adalah Unity versi 4.6.Unity merupakan aplikasi yang digunakan untuk membangun game 2D maupun 3D. Bahasa yang digunakan pada Unity yaitu C\#.

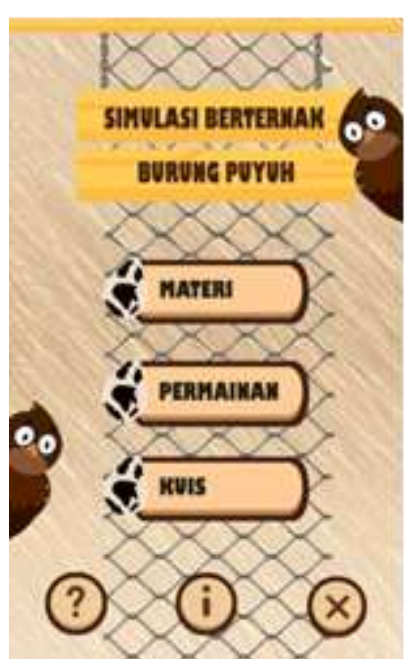

Gambar 5. Tampilan menu utama

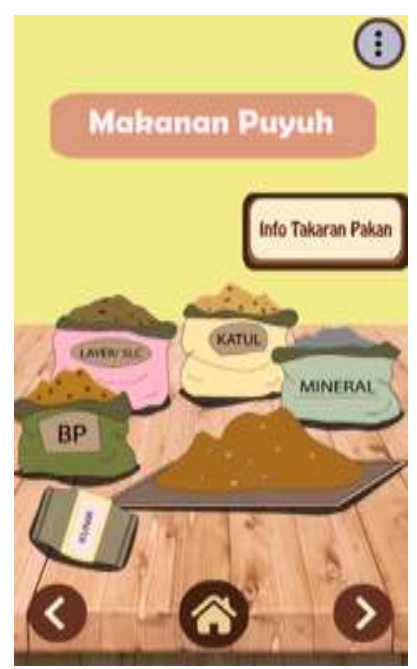

Gambar 6 Tampilan materi simulasi

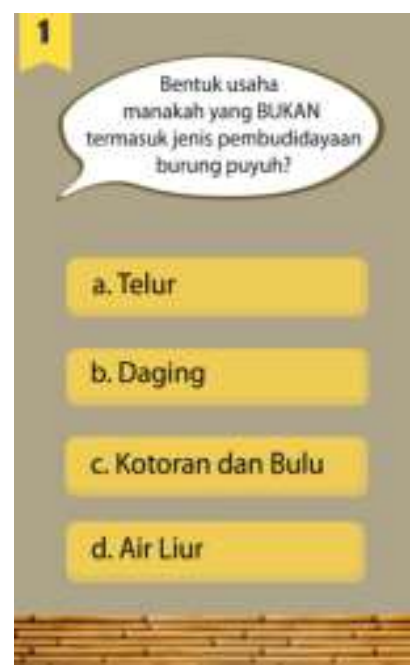

Gambar 7 Tampilan kuis evaluasi 


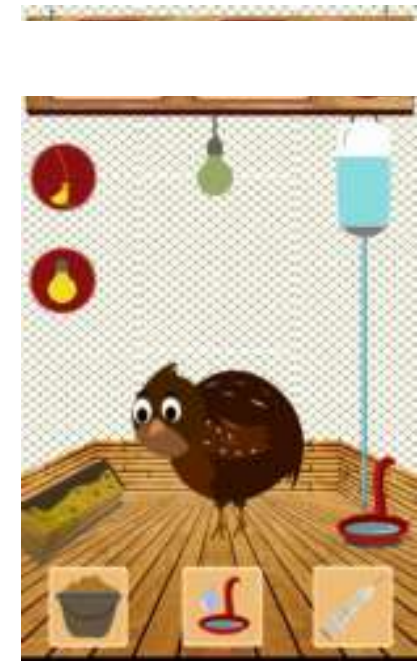

B. Penerapan FSM

Penerapan FSM bertujuan agar pengguna dapat dengan mudah memahami cara berternak burung puyuh khususnya dalam hal pemeliharaan dengan sistem pembelajaran perawatan dan pemeliharaan burung puyuh. Penerapan FSM pada aplikasi ini dipengaruhi oleh event (e) dengan parameter umur dan waktu dan juga action (a) yaitu aksi pengguna berupa perlakuan yang diberikan kepada burung puyuh. Berikut tabel kegiatan yang perlu dilakukan Selma pemeliharaan burung puyuh [5][6]

Tabel 3 Kegiatan Pemeliharaan

\begin{tabular}{|c|c|c|}
\hline \multirow{4}{*}{\begin{tabular}{|l} 
Umur \\
1 hari \\
7 hari \\
14 hari \\
30 hari \\
37 hari \\
2 bulan \\
5bulan \\
\end{tabular}} & Waktu & Kegiatan \\
\hline & Pagi & $\begin{array}{l}\text { Memberi makan, minum, } \\
\text { vaksin, dan membersihkan } \\
\text { kandang }\end{array}$ \\
\hline & Sore & Memberi makan dan minum \\
\hline & Malam & Memberi penerangan lampu \\
\hline
\end{tabular}

Berikut diagram state FSM permainan pemeliharaan burung puyuh yang mencangkup proses permainan pemeliharaan burung puyuh secara keseluruhan terdiri dari kondisi awal (Q0), Menentukan umur (Q1), menentukan waktu (Q2), menentukan perlakuan dengan fitur yang tersedia (Q3), perilaku objek terhadap perlakuan yang diberikan (Q4), kondisi mati (Q5), kondisi afkir (Q6), kondisi akhir (Q7) digambarkan pada gambar 9.

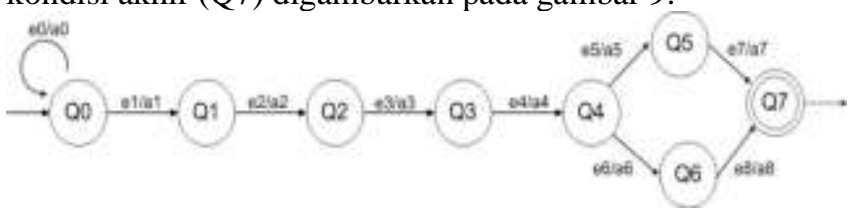

Gambar 8 Diagram state FSM Permainan pemeliharaan

Permainan pemeliharaan menckup beberapa fitur dimana setiap fitur memiliki fungsi masing - masing dan dapat mempengaruhi perilaku burung puyuh. Perilaku yang dapat terjadi pada burung puyuh yaitu sehat, lesu, sakit, stress, dan mati. Berikut pada gambar 10 menggambarkan diagram state FSM fitur makanan untuk memberi makan burung puyuh [7][8].

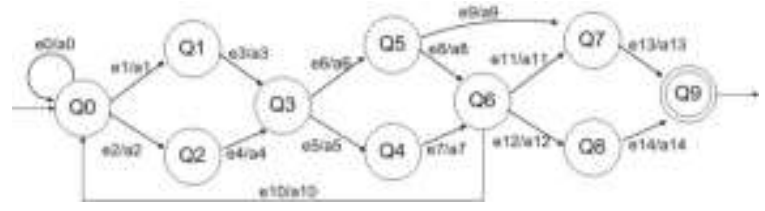

Gambar 9 Diagram state fitur makanan

Adapun state tersebut meliputi kondisi awal (Q0), umur (Q1), waktu pagi (Q2), waktu sore (Q3), kegiatan makan (Q4), kondisi lesu (Q5), kondisi sehat (Q6), menampilkan perilaku (Q7), mati (Q8), afkir (Q9), kondisi akhir (Q10).

Potongan kode program fitur makanan permainan permainan pemeliharaan burung puyuh menggunakan metode FSM yang mempengaruhi perilaku burung puyuh adalah sebagai berikut,

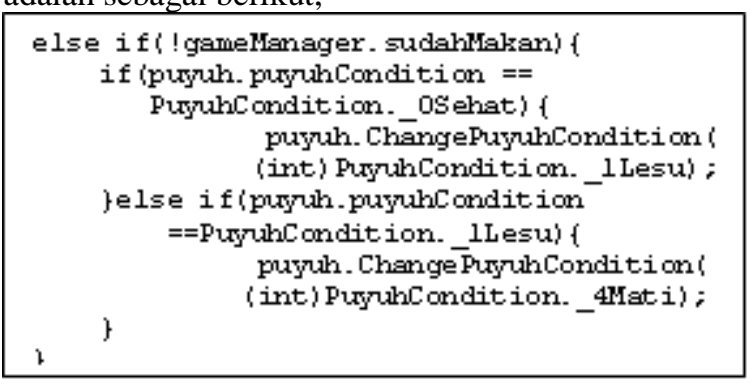

Pada gambar 11 menggambarkan diagram state FSM fitur minuman untuk memberi minum burung puyuh. Adapun state tersebut meliputi kondisi awal (Q0), umur (Q1), waktu pagi (Q2), waktu sore (Q3), kegiatan minum (Q4), kondisi lesu (Q5), kondisi sehat (Q6), menampilkan perilaku (Q7), mati (Q8), afkir (Q9), kondisi akhir (Q10).

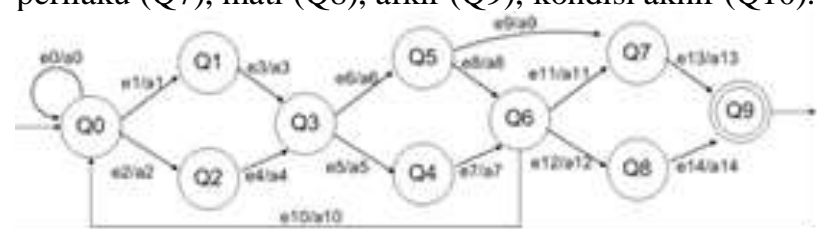

Gambar 10 Diagram state fitur minuman

Potongan kode program fitur minuman permainan permainan pemeliharaan burung puyuh menggunakan metode FSM yang mempengaruhi perilaku burung puyuh adalah sebagai berikut,

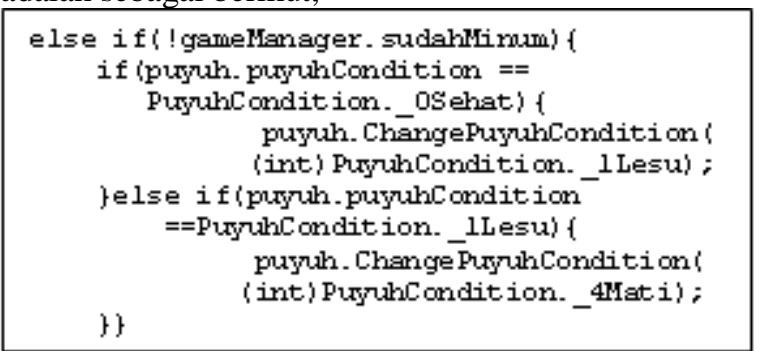

Pada gambar 12 menggambarkan diagram state FSM fitur vaksinasi untuk memberi vaksin burung puyuh. kondisi awal (Q0), umur (Q1), waktu pagi (Q2), kegiatan vaksinasi (Q3), kondisi sakit (Q4), kondisi sehat (Q5), menampilkan perilaku (Q6), mati (Q7), afkir (Q8), kondisi akhir (Q9). 


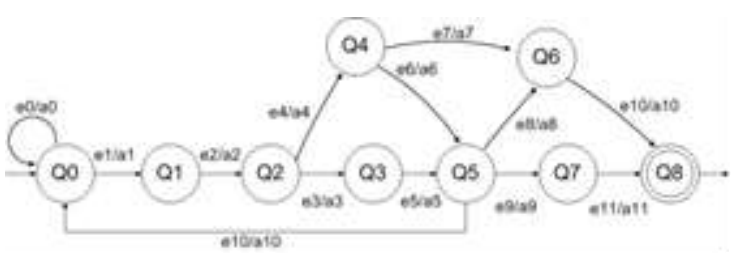

Gambar 11 Diagram state fitur vaksinasi

Potongan kode program fitur vaksinasi permainan permainan pemeliharaan burung puyuh menggunakan metode FSM yang mempengaruhi perilaku burung puyuh adalah sebagai berikut,

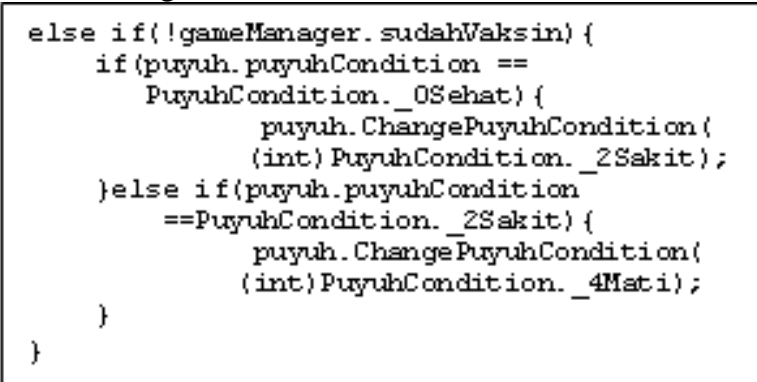

Pada gambar 13 menggambarkan diagram state FSM fitur sapu untuk membersihkan kandang ketika kandang kotor. Adapun state tersebut meliputi kondisi awal (Q0), umur (Q1), waktu pagi (Q2), pembersihan kandang (Q3), kondisi sakit (Q4), kondisi sehat (Q5), menampilkan perilaku (Q6), mati (Q7), afkir (Q8), kondisi akhir (Q9).

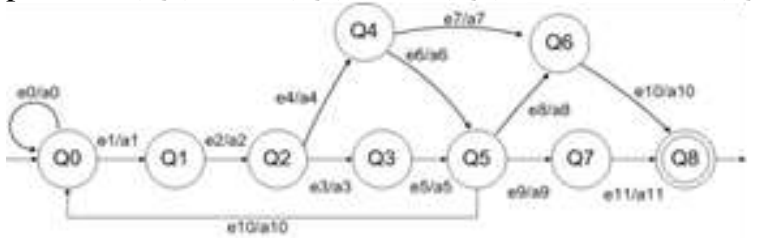

Gambar 12 Diagram state fitur sapu

Potongan kode program fitur sapu permainan permainan pemeliharaan burung puyuh menggunakan metode FSM yang mempengaruhi perilaku burung puyuh adalah sebagai berikut,

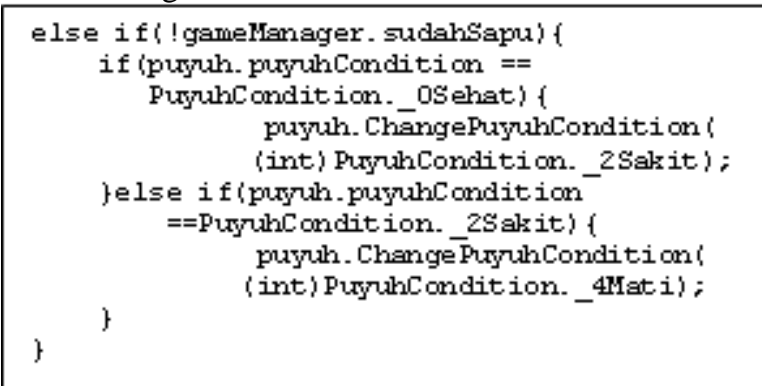

Pada gambar 14 menggambarkan diagram state FSM fitur lampu untuk menyalakan lampu kandang ketika malam. tersebut meliputi kondisi awal (Q0), umur (Q1), waktu malam (Q2), menyalakan lampu (Q3), kondisi stress (Q4), kondisi sehat (Q5), menampilkan perilaku (Q6), mati (Q7), afkir (Q8), kondisi akhir (Q9).

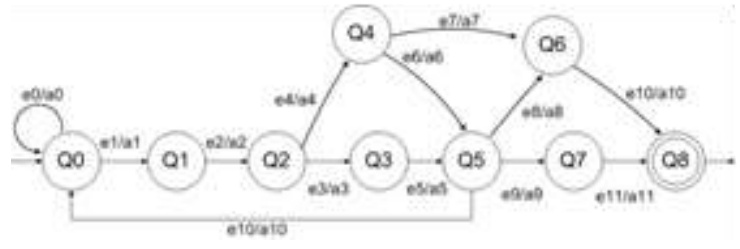

Gambar 13 Diagram state fitur lampu

Potongan kode program fitur lampu permainan permainan pemeliharaan burung puyuh menggunakan metode FSM yang mempengaruhi perilaku burung puyuh adalah sebagai berikut,

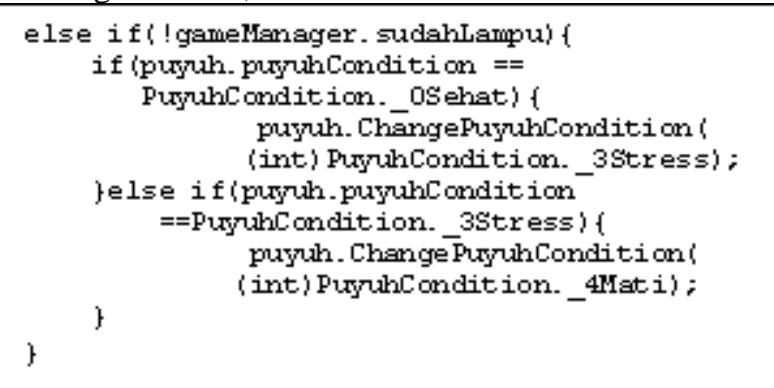

\section{Pengujian}

Pengujian aplikasi yang pertama dilakukan dengan pengujian usabillitas (usability testing). Pengujian usabilitas dimaksudkan sebagai pengujian fungsional atas kemudahan dalam mengoperasikan aplikasi dan kesesuaian alur tampilan dengan rancangan. Pengujian ini dilakukan pada aplikasi dengan 3 versi yang kemudian menghasilkan kesimpulan tampilan aplikasi yang user friendly.

Pengujian selanjutnya dilakukan dengan menyebar kuesioner kepada user yang dituju. User digolongkan menjari beberapa kriteria,diantaranya peternak puyuh yang berpengalaman, orang awam yang tidak mengetahui pengetahuan tentang berternak burung puyuh, pegawai yang akan memulai usaha berternak burung puyuh. Penyebaran keusioner dimaksudkan untuk mengetahui aplikasi dapat diterima dan membantu pengguna mempelajari kebutuhan dan proses yang dilakukan dalam berternak burung puyuh.

Tingkat kepuasan pengguna yang didapat dari hasil kuesioner yang telah dibagikan kepada 15 orang dapat disimpulkan bahwa tingkat kepuasan pengguna dalam menggunakan aplikasi yang sebesar 77,7\%. Dalam tingkat penguasaan aplikasi sebesar 64,2\% dan kepuasan pengguna dalam dalam pemanfaatan aplikasi sebesar $35,8 \%$. Sehingga didapatkan tingkat kepuasan pengguna secara keseluruhan yaitu sebesar $77.7 \%$.

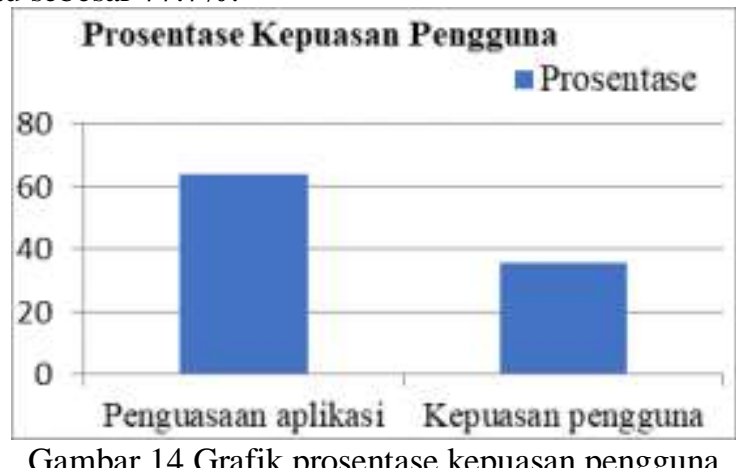

Gambar 14 Grafik prosentase kepuasan pengguna 


\section{KESIMPULAN}

Simulasi pembelajaran berternak burung puyuh mampu memberikan pengetahuan mengenai kegiatan dan proses yang terjadi selama pemeliharaan burung puyuh dengan tingkat kepuasan pengguna sebesar $77,7 \%$, sehingga aplikasi ini dapat digunakan sebagai media pembelajaran berternak burung puyuh. Penerapan metode Finite State Machine dinilai mampu dalam menentukan perilaku. Dengan demikian penggunaan metode FSM dapat memberikan pengaruh terhadap aksi yang diberikan oleh pengguna terhadap sistem.

Penelitian masih dapat dikembangkan menjadi aplikasi game simulation yang lebih kompleks lagi dalam simulasi berternak burung puyuh seperti memperbanyak scene bersifat simulasi pada kegiatan mencuci telur, menetaskan telur puyuh menggunakan mesin tetas, penanganan pada saat terdapat puyuh yang sakit, memanen telur puyuh serta dapat memperbaiki desain dan animasi konten agar lebih menarik.

\section{REFERENSI}

[1] S. Rostianingsih, G. S. Budhi, and H. K. Wijaya, "Game Simulasi Finite State Machine Untuk Pertanian dan Peternakan," pp. 2-7.

[2] A. Badruddin, "Perancangan Dan Implementasi Finite State Machine Pada Game 'Castle of Illusion,"' 2019.

[3] I. Setiawan, "Perancangan Software Embedded System Berbasis FSM," pp. 1-2, 2006.

[4] S. R. Hernawan, "Penerapan Metode Finite State Machine Pada Game 'The Mahasiswa' Guna Membangun Perilaku Non Playable Character," 2018.

[5] C. Annubaha, "Implementasi Finite State Machine ( Fsm ) Pada Game 3d Edukasi Bahasa Arab," 2014.

[6] T. Bimantoro and H. Haryanto, "Pemodelan Perilaku Musuh Menggunakan Finite State Machine (FSM ) Pada Game Pengenalan Unsur Kimia," vol. 1, no. 3, pp. 210-219.

[7] M. M. Hanafi, "Game Tukkarmatika Berbasis Android Menggunakan Metode Finite State Machine Dan Algoritma A*."

[8] F. Marzian and M. Qamal, "Game Rpg 'The Royal Sword' Berbasis Desktop Dengan Menggunakan Metode Finite State Machine (FSM)," J. Sist. Inf., pp. 61-96.

[9] Fahri(2014,Juli 13). Usaha Kecil Budidaya Ternak Puyuh. [Online] Tersedia : http://www.usaharumahan19.com/2014/07/usaha-kecilbudidaya-ternak-puyuh.html

[10] Cahyono, Duto Sri.( 2014, juni 5). Berbagai Peluang Usaha Bidang Peternakan Budidaya Burung Puyuh. [Online] Tersedia : https://omkicau.com/berbagai-peluang-usaha-bidang-peternakanperkebunan/budidaya-burung-puyuh

[11] Fahri(2014,Juli 13). Usaha Kecil Budidaya Ternak Puyuh. [Online] Tersedia : http://www.usaharumahan19.com/2014/07/usaha-kecilbudidaya-ternak-puyuh.html 